\title{
Team Learning
}

\section{Through the Relational Dynamics of Co-operation and Rivalry in Team}

\section{Communities}

Lotz, Maja

Document Version

Final published version

Publication date:

2008

License

CC BY-NC-ND

Citation for published version (APA):

Lotz, M. (2008). Team Learning: Through the Relational Dynamics of Co-operation and Rivalry in Team Communities. Department of Business and Politics. Copenhagen Business School.

Link to publication in CBS Research Portal

\section{General rights}

Copyright and moral rights for the publications made accessible in the public portal are retained by the authors and/or other copyright owners and it is a condition of accessing publications that users recognise and abide by the legal requirements associated with these rights.

\section{Take down policy}

If you believe that this document breaches copyright please contact us (research.lib@cbs.dk) providing details, and we will remove access to the work immediately and investigate your claim. 


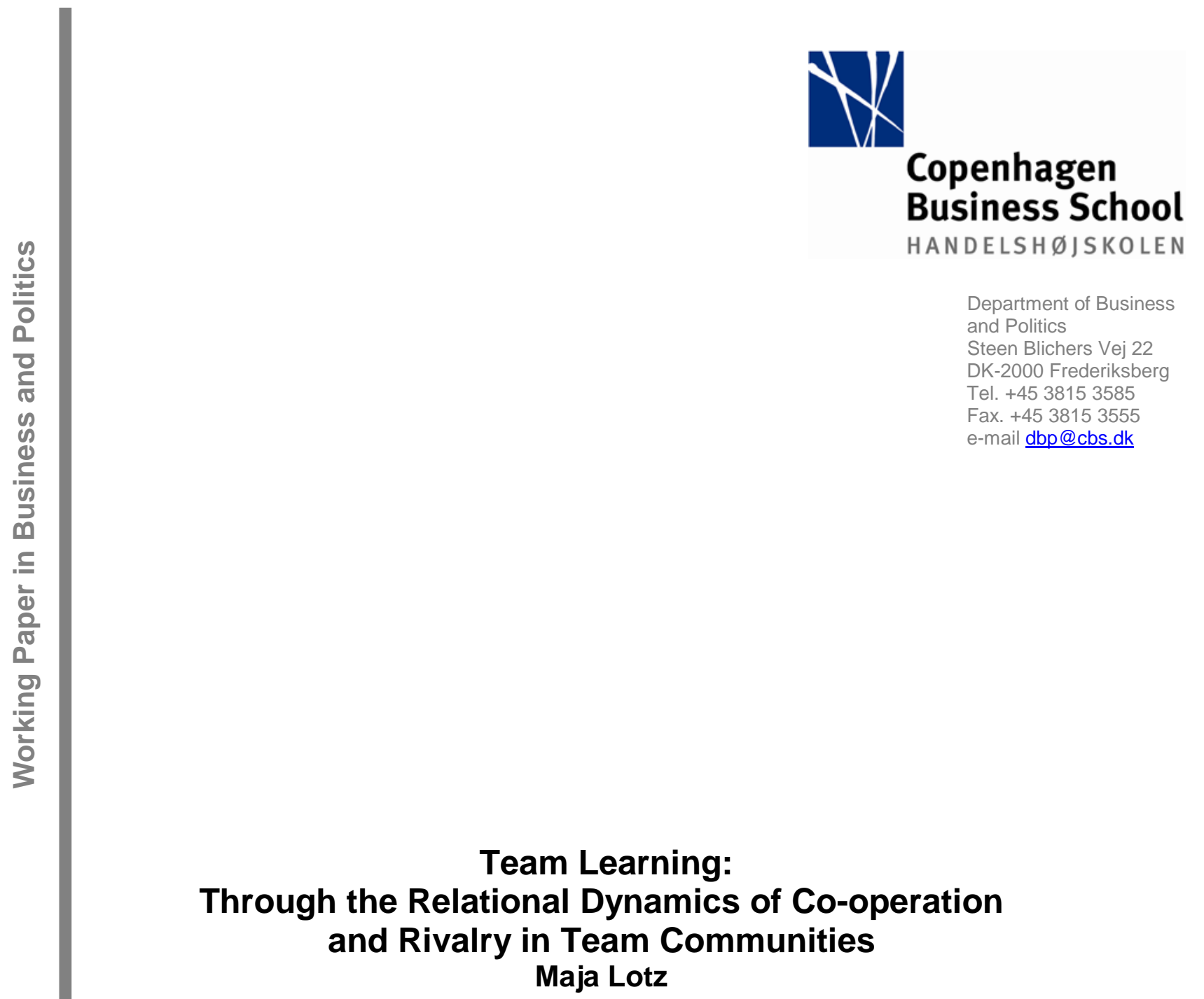


Working paper no 55, 2008

Editor: Lars Bo Kaspersen

Department of Business and Politics

Copenhagen Business School

Steen Blichers Vej 22

DK-2000 Frederiksberg

Phone: +45 38153585

E-mail: dbp@cbp.cbs

www.cbs.dk/dbp

ISBN 87-91690-99-4 
Team Learning:

Through the Relational Dynamics of Co-operation and Rivalty in Team Communities

by

Maja Lotz, ( m1.cbp@.cbs.dk )

International Center for Business and Politics,

Copenhagen Business School

Steen Blichers Vej 22, 2000 Frederiksberg, Denmark 


\begin{abstract}
In this paper I explore the constructive links between co-operation, rivalry, and learning within the structure of team communities. Drawing upon social learning theory, the main purpose of this paper is to argue that both co-operation and rivalry are important triggers for mobilizing learning processes within and between teams. However, social learning theory tends to disregard the positive aspects of rivalry. Consequently, this paper will argue for the need to extend social learning theory beyond its rather harmonious learning perspective.
\end{abstract}

Key Words: Team Communities, Rivalry, Co-operation and Learning

\title{
Introduction
}

Within the field of team-study, researchers argue that the ability of teams to create continuous learning, development, and innovation is strengthened through the establishment of equal relations of co-operation. However, critics of teamwork often claim that this work form constructs an illusion of equality and harmony among team members; in that feelings of superiority and inferiority are abandoned in the name of an ideal of equality, co-operation and fellowship. Instead, they point toward the fact that embedded in the heart of teamwork is an inescapable tension between co-operation and competition (rivalry will be used synonymously in the paper - Sennett 1998; Hocschild 1997; Casey 1998; Sinclair 2002). While many of the critics highlight this tension as strictly negative and damaging for the work life of team members, this paper argues that the tension between co-operation and rivalry (if dealt with more explicitly on both a theoretical and practial level) is not necessarily negative. On the contrary, it may potentially be what sets the agenda for elaborating on organizational means to construct the organization as a dynamic learning community of teams, and the individual team as a vibrant learning community within this community.

The principle of this paper is to pursue and explore the argument that co-operation and rivalry may both act as vital sources of learning within and between team communities. More precisely, I am interested in investigating how different team communities (team communing practices) produce/create intra- and interrelations of co-operation and rivaly, and how these team-based constitutive 
practices lead to dynamic learning processes within and between teams ${ }^{1}$. However, while aspects of learning through co-operation in teams have been discussed to a much greater extent within the learning literature as well as in team-studies (see for instance Wenger 1997; Brown \& Duguid 1991; Hvenegaard, Jessen \& Hasle 2003), less explicit attention has been given to the dimension of rivalry as a trigger for mobilizing learning processes. Consequently, the rivalry dimension and its impact on learning will be the primary focal point of this paper. My interest in this paper lies in the impact of co-operation and rivalry on learning at both the individual and team level. ${ }^{2}$

Structure: In order to explore the relational dynamics of rivalry, cooperation, and learning in team communities I shall first examine how teamwork and learning are related. Secondly, I will outline the paper's learning perspective. From here, I will turn to the concept of rivalry in order to explore how this phenomenon may contribute to learning. Then move on to present some empirical hints of rivalry from the paper's two case studies. Finally, I will sum the paper's findings and discuss how our understanding of rivalry as a trigger of learning can be advanced.

\section{Background and the Paper's Empirical Basis}

This paper is a tentative, "partial-excursion" through my longer Ph.D. journey, which addresses the roles and productive energies of communing within contemporary team-based work organizing practices. The role of novel collaborative and communing practices in and between relational team settings, as triggers for learning, creative co-design, innovative change, and co-experimental governance are explored in particular. Using qualitative case studies, I have investigated these dynamics in seven Danish production companies. As part

\footnotetext{
${ }^{1}$ In this paper, team community is understood as a constitutive practice of organizing relations among team members and teams. Thus it is defined as a "relational setting", constituted by both endogenous and exogenous relations. In this light, a team community is not just conditioned by internal relational patterns among its members, but also by virtue of its relations to other teams and the wider organizational context (Kristensen $\&$ Lotz 2005). Furthermore, I will (often) use the verb form, team communing, to highlight the processual character of the notion of team community - hereby seeking to overcome what Elias calls the problem of "process-reduction" (i.e. the reduction of processes to static conditions) (Elias 1978: 112). With this I wwish to emphasize that the concept of team community does not represent a predefined fixed "entity" but reflects a relational concept which continuously is constituted (and re-constituted) in the very process of interaction (i.e. it is always articulated and constituted in social relations) (Emirbayer 1997).

${ }^{2}$ I will clarify my understanding of the reciprocal connection between the two levels later on in the paper.
} 
of this research journey, I have discovered a puzzling paradox vis-á-vis how the dynamics of team learning within and between teams seems to unfold empirically - since (contrary to the dominant picture of team learning as a primarily harmonious and consensus based process) not only equal relations of co-operation but also rivalry appear to have a positive effect on team members' aspirations and capacities to learn. Several of the team communities under study do not simply carry out a well-defined set of activities and routines but have also been delegated the responsibility for continuous improvements of work routines and innovative changes. Within such team-based relational settings, a reflexive practice of mutual learning is pivotal to the teams' ability to improve and innovate. As indicated, these reflexive team organizing practices apparently do not only emerge through co-operation, but also seem to be closely linked with internal relations of rivalry over e.g. who is the 'best' man (or woman) on the team, who is best at teaching others, who is ascribed recognition or given most credit, or with external relations of rivalry over e.g. which teams generate the smartest new ideas, improvements or best performance results. It is this (apparent) contradiction that sets the scene and is the driving force behind this paper.

I will address the contradiction empirically by using data from two of the Ph.D. project's case studies, which are still underway and have not yet reached any analytical conclusion. The two case study organizations; Train Ltd. and Tools Ltd. respectively operate in the transport and steel industries in Denmark, and have around 10 years of experience with the teambased work model ${ }^{3}$. However each company has developed its own form of team organization - thus representing two different relational structures of team communities (or team communing processes), in which distinct dynamics of co-operation and rivalry unfold ${ }^{4}$. The methods deployed in the case studies include formal and informal interviewing, observations and secondary data obtained on specific information from each site. The selection of the two cases is purely strategic. They are selected because they are particularly rich in information about the significance of rivalry and team learning - and to be frank, because such extreme cases are well suited for getting my points about rivalry across. In the

\footnotetext{
3 The case study organizations are referred to by way of pseudonyms.

${ }^{4}$ Tools Ltd. produces cutting tools, nails, nail guns, and offers production optimizing consultancy services, tool management as well as education and training. The Danish head quarters employs approx. 500 people. Train Ltd. produces, rebuilds, and restores trains. It is part of a multinational corporation within the transport industry and employs approx. 400 people.
} 
light of my eclectic approach and the exploratory nature of the research process, I have no ambitions of generalizing the "findings" from the two cases or delivering any solid answers or conclusions about the nature of rivalry and learning in team communities. In a more tentative way, I shall empirically, as well as theoretically, attempt to pin-point some of the constructive links between co-operation, rivalry and learning in order to further our understanding of the productive forces of rivalry - a phenomenon which is habitually constrained by taboo in daily life and either neglected or treated implicitly within most learning perspectives.

\section{Team work and Learning in Team Communities}

Let me start at this point with a brief outline of how teamwork and learning are normally related or matched within team literature. Among team researchers, it is widely recognized that the conditions for learning are intimately bound up with work design. Teamwork is generally seen as one of the more favorable forms for work organization, when it comes to fostering learning within organizational contexts (Innnoflex Research Report, 2003). One of the central reasons for this is that the work form stresses factors such as worker autonomy, collaboration, and codetermination. Additionally it involves a movement towards job enrichment instead of a Tayloristic division of work, the use of workers knowledge, continuous skill development and the reintegration of conception and execution (Pruijt 2002; Benders 2006, 2002, 1999). In this way, the work model not only emphasizes the importance of formal training and instruction, but also the pivotal role of informal practicebased learning through co-operation, mutual reflection and continuously knowledge creation and diffusion among team members. Precise designs for teamwork, however, vary considerably; some team models offer very little by way of employee empowerment, autonomy, and scope for mutual learning and diffusion of knowledge, while other team designs enable autonomous reflection to a much greater extent and indeed autonomous reflection upon such actions through decentralization and empowerment (e.g. lean teams vs. socio-technical teams). Despite these variances, the outcome of team work is commonly linked to increased learning capacity and better competitiveness - In fact this trinity is often "lauded" as the overall rationale for the organizing practices of team work (Arnal, Ok and Torres 2001; Hills 2001; Gold: 2005). 
In terms of learning, Peter Senge has argued that "the rate at which organizations learn may become the only sustainable source of competitive advantage" (Senge 1990: 3). Yet, while the rate of learning is one thing, the way in which we actually learn in organizations is another. In my view, the latter concern is a precondition of the success of the former, if we wish to enhance our knowledge on how the learning rate, or in other words the ability to learn, innovate and make continuous improvement in team organizations can be improved. For instance we may ignore important insights if we solely see learning in organizations as something that is always good, harmonious, and consensus-based and which can only be activated and accomplished through managerial achievements (See for example Peter Senge 1990; Kofman and Senge 1990). Accordingly, we might blind ourselves, and not discover central learning dynamics, if we exclusively stick to a socially-oriented but primarily non-conflictual perspective on learning - where learning is understood as the act of participation and interaction/transaction in communities of practice (See e.g. Etienne Wenger 1997; Silvia Gherardi 2001). In the following, I shall briefly outline the paper's learning perspective and pin-point how it attempts to contribute to existent perspectives on learning in team communities.

The understanding of learning that I propose in this paper can be traced back to the tradition of social learning theory (in this paper primarily represented by Wenger). This theoretical tradition has the practice-based forms of learning as its primary focus. Within this perspective, learning is conceived as an integral and inseparable part of social practice, and consequently experience is seen as the crucial source of learning (Gheradi 2000, 2001; Kolb, 1974). It implies that "the learned" is a result of engaging in the actual process of interaction and performance. In this view, learning is never a "one (wo)man show", but a relational process of experiential engagement, always situated in practice - for example in the case of emerging communities of practice where learning through practice or learning-in-working is seen as the central model for learning (Lave \& Wenger 1991; Brown \& Duguid 1991). According to Wenger, learning as social participation, refers to the process of being active participants in the practices of social communities (e.g. team communities at work) and constructing identities in relations to these communities. He describes the learning process in the following way: 
"Participating....in a work team, for instance, is both a kind of action and a form of belonging. Such participation shapes not only what we do, but also who we are and how we interpret what we do" (Wenger 1997: 4)

Within this view, learning always takes place in a participatory (and hence social) framework, not in the individual mind (as a cognitive-learning perspective would stress). This kind of relational learning view, does not imply a disregard of the individual, but a perception of the individual as part of a community (Elkjaer 2000). In this sense, a distinction between the individual and the social (or team or organization) is no longer possible. The two dimensions are mutually constitutive. They produce each other and are therefore, simultaneously, products of each other, linked by a process of mutual formation (Bramming 2006; Emirbayer 1997). In this way, the learning process both embodies an "inter-cranial" and a "social" dimension, which are reciprocal and hence can only be separated at an analytical level.

The theory's focus on the practice-based forms of learning makes it well suited to exploring and understanding the learning dynamics within and between team communities. However, in my search for how both co-operation and rivalry may trigger the learning processes in teams, the social learning perspective tends to disregard one aspect; the notion of rivalry. Let me illustrate my point by listing Wenger's nine forms of relations that contribute to constellations of communities of practice:

1. Sharing historical roots

2. Having related enterprises

3. Serving a cause or belonging to an institution

4. Facing similar conditions

5. Having members in common

6. Sharing artifacts

7. Having geographical relations of proximity or interaction

8. Having overlapping styles of discourses

9. Competing for the same resources (Wenger 1997: 127)

\footnotetext{
${ }^{5}$ Within a relational perspective, individuals, (team) communities or organizations are conceived as inseparable from their relational context. Mustafa Emirbayer elaborates on this by quoting Cassirer in the following way:

"[Things] are not assumed as independent existences present anterior to any relation, but...gain their whole being....first in and with the relations which are predicated of them. Such "things" are terms of relations, and as such can never be "given" in isolation but only in ideal community with each other" (Cassirer i Emirbayer 1997: 287).
} 
A brief look at Wenger's list indicates that the character of relations is primarily described through terms like sharing, having related, facing similar, in common, and overlapping. Connotations that arise from this list, relate to unity and harmony rather than conflict and rivalry. Only, the last form of relationship - competing for the same resources - directs our attention to a potential conflict of relations; unstable balances of power, inequality, discord and rivalry within communities of practice. But all in all, it is cohesive, harmonious associations and images of learning that tend to dominate Wenger's theoretical universe. Quite contrary to Wenger's intentions (he does not neglect power and competition, and several times emphasizes the conflictual nature of social practice), this shortcoming downplays the dynamic tensions and struggles within a (team) community and hence their potential impact on learning in such participation practices. The limitation of unifying intimations in both Wenger and Lave's approach has been pointed out by several authors (Bottrup 2003; Gherardi et al. 1998; Henriksson 2000). In the following extract, Kristina Henriksson comments on how the unifying intimations reveal themselves in Wenger and Lave's empirical illustrations:

"Their examples from ethnographies of practices... express rather smooth socializing trajectories as individuals engage in practice, gradually align their actions to, and take babits and language of a larger collective. Although the authors argue analytically against romanticizing communities of practice....potentially bumpy community rides are to a large extent absent from ensuing illustrations" (Henriksson 2000: 11).

Pernille Bottrup criticizes their rather non-conflictual approach in a similar vein. Although in some points, Lave and Wenger demonstrate that they have an eye for the potential power games involved in becoming accepted as a participant in the community - once they acknowledge a participant is accepted, they conceive of learning processes within a given community of practice as a rather harmonious and unproblematic mutual engagement furthered by aligned action, trust, dialogue, cooperation and joint constructions of meaning (Bottrup 2003). In this construction, learning seems to be a fairly harmonious trust-based form of adjustment to the community of practice. One decisive problem within such a perspective is that learning processes tend to reproduce the existent. A parallel shortcoming to this would be e.g. the limits of Argyris and Schön's single-loop learning or Senge's similar 
adaptive learning type (Agyris \& Schön 199?; Senge 190). At least, it is difficult to see how new routines, a constant re-definition of roles, beliefs and ideas or co-innovative change can nourish in an environment that praises unity and excludes the bumpy rides of communing in the name of harmony and passive adjustment. Over time, such social worlds rest on an inevitable propensity to merely reproduce practice and hence kill creativity, since they abandon how diversity, conflicts, problematic situations or power struggles may also act as resources that spur processes of change, reflection and re-creation. i.e. These are processes that allow us to continuously re-cognize, re-configure, re-combine, re-define, re-create and re-organize for example ourselves, knowledge, ideas, technology, work tasks, routines, products, services etc. for further creation within organizational life. Learning in team communities hopefully is therefore more than mere processes of adjustment to the existent. Hopefully, not at least because the team work model is often implemented with the very purpose of enhancing organizations' abilities to innovate, challenge habits and routines, and strengthen their readiness for change. Thus, a solely harmonious perception of learning is not very fruitful if one wants to explore how reflexive practices of mutual learning may facilitate the production of new ideas, the aspiration to come up with smarter ways of doing work, and creating a work environment where doubt and curiosity towards the existing work practice create the basis for innovative changes and continuous improvements. Accordingly, my argument in this paper will be to extend social learning theory beyond its' broad and harmonious understanding of learning by illuminating how rivalry and not only equal relations of co-operation may trigger the learning processes within contemporary high performance team communities.

Another shortcoming within many social learning theories is that the actual learning processes and the concrete learning mechanisms are treated as 'black boxes'. It is indeed liberating to see how these theories have allowed learning to enter the social field - and added social considerations to the usual (and often simplistic) focus on individual learning. However the trade off for this, often seems to be a very broad (and hence vague) conceptualization of learning. When these approaches define learning as something that takes place when we participate in and across communities of practice (or other social settings) the phenomenon becomes omnipresent - and thus resembles the very process of socialization or participation in life. For instance, Wenger repeatedly describes learning as the 
act of living (Wenger 1997, 2004). Consequently, learning tends to cover everything and nothing at the same time - and therefore ends up as a very blurred concept/process within most practice based learning theories. Questions such as - how do we learn through participation? What triggers our actual learning processes? Or how are both action and thinking or mind and body involved in our collective learning practices? - thus become genuinely difficult to explore from a strictly social learning perspective. The work of the American pragmatist John Dewey, however, does confront the questions of how we actually learn. In arguing for a new learning perspective that encompasses the "learning-aspects" of both co-operation and rivalry, I will later introduce and draw upon Deweys understanding of learning and experience. In this way, I will place the "how" of learning within and between team communities at the core of my explorative approach. However, first I will turn to the concept of rivalry in order to explore how this phenomenon may contribute to learning.

\section{Approaching rivalry - a phenomenon constrained by taboo}

For many people (including me), the term rivalry has, at first glance, a rather unpleasant flavor. One reason may be that it points to conflict, struggles and unequal balances of power as an integral element of all human relationships. These connotations do not immediately correspond to present-day democratic values, such as liberty, equality, and solidarity (at least not within a Danish/European context). Cas Wouters describes the era after the Second World War as a period: "of expanding interdependencies and rising levels of mutual identification, in which ideals of equality and mutual consent spread and gained strength" (Wouters 1998: 143). He argues that the ideal of equality allows for an informalization of our emotional life on the one hand, but on the other hand imposes a ban on expressing feelings of extreme inferiority or superiority, because such feelings do not "match" the equality-figuration of our time. He describes this avoidance in the following extract:

"The insight that feelings of inferiority and superiority are inherently provoked by any status competition tended to be banned, and the same goes for the insight that part of any encounter or gathering is a 'trial of strength', a power and status competition. Thus, during the same period in which many emotions were allowed to (re)emerge into consciousness and public life...., simultaneously the emotions connected with triumphs and defeats were becoming 'strange' to the self' (Wouters 1998: 143). 
According to Wouters, competition or rivalry, understood as trials of strength over power, status or success, exist as everyday occurrences and intrinsically provoke feelings of inferiority and superiority. Experiencing or displaying such feelings, however, have become extremely taboo - and are consequently banished to the realm of imagination and sports, or hidden behind social and psychic fronts. In this light, the offensive connotations which cling to the concept of rivalry seem quite comprehensible. Although, feelings of undisguised inferiority or superiority are banned from, what Goffmann would call, our front stage, they naturally do not vanish from social life. Instead one's own demonstrations of distinctiveness, 'trials of strength' or what has in this paper been named as rivalry seem to become more indirect, subtle and hidden.

Despite the taboo face of rivalry in all aspects of our social life, relations of rivalry recur again and again. We know the trials of strength from school: Am I better? - are you better? The competition in children's games or between brothers and sisters. We know of rivalry at work, between colleagues striving for promotion, status or recognition. We compete in sport and within our capitalistic market, competition is the basic ordering structure both in a structural and an ideological sense. The list of ccurences in which rivalry can make itself felt is endless. It illustrates that even though social codes dictate the avoidance of inferiority and superiority feelings, rivalry is an integral form of social interaction in society.

In the following, I will try to look more closely at the character of rivalry and its significance, in order to track down some general links between co-operation, rivalry and learning on a theoretical level. For this "experiment" I will draw upon three relational thinkers, the notion of conflict and John Dewey.

\section{The significance of rivalry from a theoretical perspective}

Grasping the character and significance of rivalry is by no means a clear-cut matter and is first and foremost something which must be determined empirically (since practice always gives words their meaning - cf. Wittgenstein). However, eclectically drawing upon Norbert Elias, Georg Simmel, and Johan Asplund preliminary I will briefly identify some of its central features before relating it to learning. First of all, Elias emphasizes that engaging in trials of strength over power balances are among the basic properties of all human relationships 
(Elias 1978: 78, 175). Accordingly, Asplund describes rivalry as a form of elementary social interaction which is characterized by a struggle over some kind of object. The object can be either material or symbolic (e.g. resources, power, social prestige, status or success etc.), and is always characterized by scarcity. Thus the struggle cannot be understood without an object (Lind: 2001). This further implies that interactions of rivalry always embody a conflict - a basic tension between contrasts striving for the same object. In this way Asplund points to another central feature of rivalry, namely its always inherent conflict and connectedness to an object.

It is commonly viewed that conflict is something that counteracts unity, while cooperation is seen as an integrative and unifying force. According to both Simmel and Asplund this is misleading because conflict is also a sociation, a form of interaction designed to resolve divergent dualisms. In this light rivalry does not always result in a break of social relations but can establish social relations as well (Asplund 1972: 57; Asplund 1989: 15-17). Additionally, Simmel shows that an ideal of a relationship free of conflict is not unifying but on the contrary disintegrative and counter productive:

"opposition gives us inner satisfaction, distraction, relief....It allows us to prove our strength consciously and only thus gives vitality and reciprocity to conditions from which, without such corrective, we would withdraw at any cost” (Simmel 1971: 75).

Consequently, conflicts or relations of rivalry seem rather to unite and increase the understanding and reciprocity between persons - instead of decreasing it in many cases. A third central feature of rivalry is thus its corrective and hence always collective character. To sum up, in Simmel's words, an absolutely harmonious relationship or group is empirical unreal, because there: "exists no social unit in which convergent and divergent currents among its members are not inseparably interwoven" (Ibid: 72). Therefore both kinds of interactions may (usually) be found in any real situation. Following this line of "gedanken", cooperation and rivalry are not complete oppositional contrasts, but interwoven forms of interactions or relationships both working as integrative forces in social life - such as e.g. between the members of contemporary team communities. 
But how does all this relate to learning? The link I propose in this paper goes like this: Simmel's quotation about oppositions highlights how we prove our strength consciously through situations of conflict and thus become aware of our reciprocity to conditions. He indicates that in this way we become able to reflect upon and be aware of "the other" as well as our own capabilities (and self). Participating in such corrective relations, I will argue, reflects a learning process, quite similar to Dewey's conception/description/understanding of how we actual learn. Let us therefore cast a glance at Deweys notion of learning. According to Dewey mere participation in practice does not create learning, because learning is a process of inquiry that includes actions as well as reflection, thinking and cognition (ie. involves our head and body). In general he defines learning as a continuous reorganization and reconstruction of experience which takes place all the time in all social situations where people act, interact, reflect and think ${ }^{6}$. Learning (understood as reflective experience) unfolds in the transaction between the individual and the situations that she/he is part of ${ }^{7}$. It always grows out of / is triggered by a situation where a person is in doubt or confused - i.e. facing a situation that is uncertain or problematic. It is a situation that makes a person stop, think, act and think again. In addition Dewey argues that knowledge is constructed by making inquiries into situations of uncertainty. When we face such problematic situations our habitual actions are upset and exactly this provocative element in experience is what creates the basis for new experiences according to Dewey. Thus, we gain new experiences as a result of inquiries into problematic situations (e.g. conflictual situations of rivalry). It is the sense of uncertainty that triggers our ability to inquiry and hence our ability to learn and relearn from experience (i.e. our actual learning processes) (Elkjær 1998, 2000; Shustermann 1999)

Moving along Simmels and Deweys thoughts, rivalry can be said to always embody or rest upon a situation of uncertainty - because of its inherent conflict (tension between contrast striving for the same object). It is so to speak forever grounded in a problematic situation

\footnotetext{
${ }^{6}$ Dewey more precisely defines what it means to learn from experience in the following way: "To learn from experience is to make a backward and forward connection between what we do to things and what we enjoy or suffer from things in consequence. Under such conditions, doing becomes a trying; an experiment with the world to find out what it is like......" (Dewey 1916: 140).

${ }^{7}$ According to Dewey: "we never experience nor form judgments about objects and invents in isolation, but only in connection with a contextual whole. This latter is what is called a "situation"” (Dewey 1938 in Shusterman 1999)
} 
that challenge existent habits and thus creates the basis for new (learning) experiences. Hence rivalry seems to provoke our former experience and thus trigger new learning processes. In this light it is namely the provocative or corrective element of rivalry that enables reflection upon former actions and practices in order to anticipate further consequences, act and think differently, change existent routines, or come up with new ideas. Relations of rivalry inevitably spur processes of inquiry into existing practices. Consequently, I argue that rivalry reflects a learning process that not only tends to reproduce the existent, but opens up for new experiences and change of habits. My argument is in many ways familiar to way in which social learning theory characterizes learning as the engagement in practice trough participation - since rivalry as cooperation represents a form of actively engagement in practice. However the two analytical learning processes are different in one respect; the harmony-based learning process, found within social learning theory, tend to reproduce the existent, while the rivalry-based learning figure, proposed in this paper, tend to trigger innovation due to the inherent conflict (problematic situation) on which it is founded. Said differently, the conflict dimension of rivalry creates an urge to challenge the existent - an urge to experiment, re-configure and re-define etc. which not is found (at least to the same extent) within learning processes through mere harmonious relations of cooperation. In the same way any trial of strength or dynamic relation of rivalry can be seen as a learning-process that to a greater extent, than learning through only cooperation, challenge the existent and thus promote change and innovation. The sketched SimmelDewey inspired learning-figure creates a vital link between rivalry and learning. It is not opposed to a traditional harmonious and collaborative-based social learning perspective. Contrary it deepens our understanding of how we actual learn, and what triggers our learning processes in the social situations or practices we engage in. The two perspectives are supplementary and should be (used) integrated. Such a two-folded analytic learning-figure takes explicitly rivalry into the terrains of social learning theory. Hence it offers a more nuanced understanding of the dynamic links between cooperation, rivalry and learning - and thus extends social learning theory beyond its primary harmonious conception of learning.

Before I attempt to demonstrate some of the empirical examples of rivalry from my field studies (with the purpose of getting a better understanding of rivalry and learning), one important reservation needs to be made. 
The significance of rivalry is clearly not always positive. It has two integrated faces, so to speak; one constructive and one destructive. Simmel also emphasizes that conflict contains both positive and negative aspects (Ibid: 71). For instance, causes of rivalry and conflict such as hate, envy, extreme jealousy or greed most often work as dissociating factors and promote destructive forms of rivalry. Likewise, total indifference between two or more persons breeds negative conflict and makes constructive relations of rivalry impossible. Further to this, the consequences of rivalry are not always positive. Stress, inferiority, feeling worn outs etc. may often represent the negative, shadow sides of rivalry. Although the destructive face of rivalry is pivotal and needs to be taken into account and prevented - it is not the focus of my paper. My sole interest is the positive aspects of rivalry and its impact on learning. Consequently, one could claim that the stories of rivalry presented in this paper tend to be of the more positive kind. However, any choice is always also a de-selection, and the mentioned limitation must be seen in the light of the paper's purpose.

\section{Approaching rivalry empirically - is a challenge!}

To empirically study the dynamics of rivalry within and between team communities is a challenge. I have asked the subjects interviewed to communicate their perceptions of and experiences with competition at work. I have especially asked them to talk about concrete situations, where they had experienced relations of constructive rivalry within their team or between teams. Their responces to my questions about rivalry were at first often negative: "No, we don't compete with each other - we are a team" or "I don't know of any rivalry between colleagues”. Given such answers, I tried to explicate the positive aspects of rivalry I was curious about; the friendly competition games, the need for recognition, discussions about status competition, as a trigger for coming up with new ideas etc. Some would call this "fishing for the 'right' answers", but at least my explications helped. Afterwards the interviewees talked much more freely about their experiences of rivalry in their daily work life. But, the fact that rivalry is hampered by taboo is reflected in the interviews. Hence the empirical material is not full of heavy and detailed descriptions of rivalry. However, through a triangulation of interviews, observations and information specific to the site, I shall outline the hints of rivalry that I encountered during my empirical study. 


\section{Hints of rivalry from the field}

To depict the distinct forms of team communities, characteristic within the case studies, and to show how they create intra- and interrelations of co-operation and rivalry, three descriptive tools have been used to guide the first phase of analysis; the team architecture (the organizational design of the teams); the team activity (the actual work process and variety of tasks performed); and the authority structure of the team (encompassing the management form and the team's decision-making power) ${ }^{8}$. In this preliminary phase, I have used these three analytical tools because they, in different (though also overlapping) ways, influence the relational setting of team communities (i.e. the pattern of relationship within and between teams). Additionally they pave the way for a new perspective on both the structural and processual elements of teamwork and learning. Using these frames to structure my field study, I have traced the stories of how relations of rivalry seem to have a positive impact on teams and team members' learning processes, within the case studies. From this basis, and as a second phase in the analysis, I have condensed the stories of rivalry. Four stories or typical situations of constructive rivalry relations have then emerged from the empirical material. These are stories centered on performing and making results, shifting roles, gaining skills and competencies, and striving for social reputation ${ }^{9}$. In the following pages, the four stories will be presented - with some general conclusions to follow in the subsequent section.

\section{Performing and Making Results}

Team-based systems of incentives, with a high degree of financial transparency are characteristic within both case-studies. According to the team workers, these systems give rise to the dynamics of rivalry over performance results, and is particularly experienced between teams, thus furthering their ability to continuously reflect upon and improve existent routines.

The companies' systems of incentives are directly designed for and targeted to create a competitive environment. For instance, in Train Ltd's teams (typically consisting of ten

\footnotetext{
8 This distinction is inspired by Bacon \& Blyton's study of high and low road team working (Bacon \& Blyton 2000) and Bacharach's dimensions of team theory (Bacharach 2004).

${ }^{9}$ The stories will not be presented as case specific practices. Traits of the stories can be found in both case studies despite differences in work products, work organization, context etc. My intention in this paper is not to compare the two case studies, but to use them equally and eclectically as the papers empirical source.
} 
skilled and unskilled workers of different professions) are created when a new contract (of say ten trains for Italy) has been concluded. This contract frames the tasks and the economy of the teams within a project. But within this frame, the team is free to find ways of producing the trains that are better and more profitable. In case it does, it can keep $50 \%$ of the gains for itself, while the rest is transferred to the plant as a whole. Thus, the teams are not only responsible for the actual production processes, but are also drawing up and implementing the budget; made accountable for their part of the project. Such an incentivebased team design encourages greater cost-consciousness and financial responsibility among the team workers, and the management stresses that it is the company's "most important tool for involving our workers and creating a competitive environment". In Tools Ltd., all employees are part of a bonus scheme through which profit sharing is based upon the previous months' surplus, and the employees are continuously informed about turnover, strategies, assessment of outcomes, etc. However in what ways do these systems create the basis for constructive dynamics of (co-operation and) rivalry?

According to the team workers, their economic systems of incentives create opportunities and aspirations for both co-operation and rivalry. The teams' responsibility for the financial management of their area in particular, and performance-pay dependent on their abilities to yield profit, enables the workers to realize that their joint actions strongly affect the profits cashed by the team. In addition a need for dialogue, close bonds of internal co-operation and daily knowledge sharing within each team is evident. In this way team-based economic incentive systems seem to nurture ongoing inquiry and reflection on how to continuously improve performance. They also appear to further awareness of the joint daily practice in the team communities through, for example, relations of mutual commitment and co-operation.

Yet, performing and achieving good results as a team is not just a harmonious and unproblematic collaborative process, since the economic incentive systems also confront the team workers with official performance targets, demands about effectiveness, or their ability to present the right competencies, as well as doubt about their own personal capabilities to match the very same demands. Facing situations riddled with uncertainty, the team workers former experiences are provoked and their existent habits challenged. According to the team workers experiences of rivalry, one key way to cope with such situations of uncertainty is to 
enter into trials of strength over the performance results they have achieved. Engaging in these relations of rivalry, the team workers make inquiries into (their) problematic situations, and thus gain new learning experiences (on, for example, how to perform better). Thus these situations seem to trigger relations of rivalry among the team workers that "force" them to continuously reflect upon their practice and improve performance results (i.e. to learn and re-learn). The high degree of financial transparency in the workplace seems, in particular, to produce an external rivalry between teams over performance results. For instance, the interviewed team workers were highly aware of both their own team performance results and that of the other teams. In addition, when asked about rivalry, they often mentioned that informal relations of rivalry among teams, such as in the case of competing for status (e.g. the desire to be the most successful team performers, the winners!) often gave rise to a "we" against "them" mentality and created the dynamics of a contest. These inter-relational dynamics of competing over comparative performance across teams, is highlighted by the teamworkers as an important motivation for getting them to suggest smarter ways of working and striving for continuous improvement within the team communing practices.

\section{Shifting Roles}

Another story of rivalry emerges from the case companies co-managing authority structure. In Train Ltd., a formal set of co-ordinating roles have been institutionalized in each team, while the same tendencies can be traced in Tools Ltd., although on a more informal and unstructured basis. As a result, team members are responsible for different co-ordinating roles and this practice of taking on and shifting roles gives rise to the constructive dynamics of rivalry within team communities.

The management philosophy in both companies is that employee-initiated decisions and ideas are easier to sustain. Thus, the authority structures invite a high degree of "autonomy" and encourage the team workers to manage themselves, their problems in relation to daily practices, (e.g. planning, division of labor, purchase, absence, vacation). Consequently they are encouraged as well as expected to actively participate in managing the daily work processes and hence take on different roles, develop with them and learn from these engagements in their practice. As indicated Train Ltd. Has, to a great extent, formalized the processes involved in shifting roles. Accordingly, in each team the position of team co- 
ordinator is divided into three roles that members of the team perform in turns. Each team has an "overviewer", who is responsible for staffing, consumption per hour, utilization etc., an "optimator", responsible for the current optimization and improvement of work processes, and a "group developer", responsible for the proper functioning of the team's social life. Overall this kind of co-managing practice seems to promote team communities of reflexive practitioners furthered by both co-operation and rivalry. Let us therefore have a closer look at these shifting role patterns.

Given that the team members perform the three co-ordinating roles by turns, they are all actively engaged in and share responsibility for the tasks and obligations of the roles.

Through this form of mutual cooperation the individual team member becomes better able to take on the roles of others, reflect on these, and thus better able to contribute to new ideas and suggestions for improvements. Such forms of co-operative role shifting within teams seems to strengthen the intra-relational learning processes within the team communities. At the same time, learning tendencies of another kind are triggered - because the co-managing practice of shifting team co-ordinator roles introduces a new competition object up front; i.e. the status and success of being role master. Being thrown into new roles is experienced by the team workers as challenges - but they also find this anxiety provoking, since it involves new situations of uncertainty and doubt towards e.g. ones personal ability to master the new roles. In order to perform the new roles successfully the team workers must constantly reflect upon former experiences and routines. Furthermore, they must compare and correct the activities of their role in the light of former role masters or their colleagues' expectations - at the same time as searching for, finding, and evaluating new and better ways to handle the roles. Great learning potentials seem to be anchored in these forms of team practices, since the process of shifting roles and/or taking on new ones inevitably embodies a problematic situation that creates relations of rivalry which trigger the team members aspirations and abilities to act and think in innovative and improving ways. According to the team workers, performing the different roles better than the worker previously in charge of the role provides personal status, and thus gives rise to competition games over who is the best role master. Striving for recognition and success as a role master seems, in this way, to strengthen the aspirations to learn from previous well performing role 
masters, and to come up with new ideas and suggestions and actively take part in the team's managerial tasks.

In addition to this, at the inter-relational team level, each team co-ordinator meets regularly with "others of their kind" from the other teams to share experiences and discuss problems connected to their roles. These inter-team activities or cross-team discussions enhance the workers' knowledge sharing, reflection, and the inter-relational dynamics of learning among the teams. At this level, rivalry may also be at stake. However, at the moment, I have no empirical findings to support such statements.

\section{Gaining skills and competencies - a professional work identity}

Stories of rivalry in relation to developing and maintaining a professional work identity are also significant. In both companies, the technological context with regard to the layout of the production system and the nature of the tasks performed provide the setting for work processes requiring proximity, close bonds of co-operation, and a constant need for a professional exchange of know how. In effect interdisciplinary collaboration, dialogue and professional exchange of information characterize the daily activities of the teams. In Tools Ltd. according to the employees, you cannot be a part of the team community if you are not willing to continuously learn and teach others. A team worker put it in the following way: "Here we are all equal, whether you are a new comer or one of the old ones we get the same salary-you can't gain anything by keeping knowledge to yourself .....success is all about knowledge sharing and collaboration". Thus an ideal of equality and relations of co-operation seem to dominate the picture within Tools Ltd., but simultaneously traits of rivalry unfold (in both case studies).

One example of rivalry is seen when professional games within the workplace also seem to become part of the team members work practices. Through rotation and continuous knowledge sharing within (and sometimes also among) teams, the management seeks to enlarge the range of variation in the team members' work tasks, their co-operation skills and their ability to shift roles within the teams. In this form of work practice, informal learning through equal relations of cooperation seems to flourish, but participation and engaging in performing the work tasks also encompasses more subtle relations of rivalry over who obtains the best professional competencies, the best skills and abilities to handle the work or 
over who is best at suggesting new improvements on the team. Such competing rivalry dynamics appear to trigger the team workers aspirations, as well as capacities to learn with and from each other. Another example of the positive dynamics of rivalry is linked to the team workers continuously upgrading through knowledge-sharing, rotation and training programs. Engaging in these activities, rivalry over being best at teaching others, managing the most work processes or improving ones skills also characterizes the workers co,operative learning culture. Such interactions of rivalry mobilize a space for learning in which more conflict based learning processes also help to continuously develop and improve the workers skills and know how. In this respect, bonds of cooperation and subtle dynamics of rivalry seem to go hand in hand as connecting drivers for mobilizing learning processes among the team workers. Thus the two examples illustrate how struggles over gaining and performing new skills and competencies as well as teaching others, seem to be vital "ingredients" in building up a professional work identity among the team workers.

\section{Striving for social reputation}

"Friendly" rivalry games over who is most often being recruited to new development projects or contests of social reputations also characterize the workers team practices.

Simultaneously, with the formal team organization structure in Tools. Ltd., provisional teams are continuously constructed across functions and operating units on an ad-hoc basis according to the required competencies and resources, that is like collaborative networks relating to a given task or project. Hence collaborative team communities of employees from different units and with different skills and competencies are assembled on an ongoing basis. Often team employees volunteer themselves to join an ad hoc team or they are picked due to special skills, competencies or reputation. Participating in these ad hoc teams is seen as a prestigious affair. To be part of such development projects strengthens the team workers social reputation or prestige. In this light rivalry relations over who is most often picked to join such projects seems to further a continuous drive for learning new competencies and gaining social reputation among many of the team workers.

These more temporary and fluctuant collective practices that criss-cross the organization's basic team settings involve significant collaborative dynamics. Hereby, assemblages of 
divergent roles, competencies and personal life trajectories become possible. According to the employees it is especially this "clash" of different competencies and interplay between divergent roles within the ad hoc teams that enable a common focus and ensures a joint commitment towards the wider organization beyond ones basic unit. By participating and engaging in different collaborative settings across units/departments employees interact and exchange knowledge and information. Hereby they gain greater knowledge about their colleagues' work functions, competencies, challenges, dreams etc. But in this process they also fight for social reputation and recognition. Through these ongoing interactions and exchanges, new collaborative figurations are constantly made which further the employees' knowledge of "otherness" and "self"- because in this way they not only learn about others but hereby they also learn about themselves. Additionally, many of the employees articulate how the integration of divergent competencies and roles enable continuous learning triggered by (engaging relations of ) both collaboration and rivalry. It is their experience that such co-creating processes result in better innovative solutions and performance results and therefore they have a common interest to engage in, develop with, and learn from these forms of collective interdisciplinary (inter team) activities.

Clearly the ongoing formation of interdisciplinary ad hoc teams and the strong learning culture appeals to cooperative skills and fellowship. But contests of social recognition and respect as well as games of professional competition are also embodied in the work practice. For instance do the team workers tell about how they sometimes on a friendly basis compete over how to perfect existing work routines or suggest new improvements within teams as well as between. In such situations the object of rivalry is not primarily performance result or extra bonus pay, but more aimed at obtaining social recognition from colleagues e.g. due to ones ideas, competence, creativity or special expertise. In this way the feelings of pride and joy from a recognizing look or a pat on the back from the team mates because of personal achievements, seem in it self to be something to struggle for. This form of rivalry apparently motivate and have positive effect on the team workers' aspirations for continuously perfecting the work processes and suggesting innovative ideas in Tools Ltd. 


\section{Rivalry as a trigger of learning}

How can these hints of rivalry be understood within social learning theory and what can social learning theory gain from them? Drawing upon a learning perspective rooted within social learning theory, paves the way for an understanding of how practice-based forms of learning unfold within and between team communities. In this context, learning occurs as a result of actively participating in and engaging in the actual process of interaction and performance in e.g. team communities. However, the learning process within the communities of practice approach is understood as a, primarily non-conflictual and unproblematic mutual engagement in action - advanced by co-operation, equality and unity. Consequently, it tends to disregard the constructive relations of rivalry. But rivalry is also a form of engagement in practice. Turning towards Simmel's notion of conflict, I have argued that rivalry can be seen as a learning process. Likewise this learning model enhances our understanding of practice and our ability to reflect upon it, but because of the inherent conflict on which it is founded, this form of learning tends to challenge the existent to a greater extent.

In the paper's two case stories, I have tried to illustrate how not only harmonious relations of co-operation and equality, but also rivalry characterize the team members' participation and engagement in their work practice. Against this backdrop, rivalry apparently works as an important trigger for learning in the team communities under study. Thus a short answer to the question above is that social learning theory provides an important framework to conceptualizing rivalry as a practice-based form of engagement and participation. However, by more explicitly embracing and integrating the dynamics of rivalry into its realm of study, social learning theory could acquire a better means for exploring and understanding the productive forces of rivalry - as well as greater insight into how they may contribute to the creation of reflexive practices of mutual learning within contemporary organizational life.

\section{Conclusion}

It is hoped that the above analysis has provided some insights into the question raised at the beginning, i.e. how different team communities create intra- and interrelations relations of 
cooperation and rivalry and how these team-based practices lead to dynamics of learning. The paper has shown that a reflexive practice of mutual learning within team communities seems to be advanced by not only equal and harmonious relations of cooperation, but also by relations of rivalry. Hence rivalry appears to have a positive impact on the team members' aspirations and capacities to learn, as well as their ability to continuously challenge existent routines in the search for improvements and better performance.

What can you, I and we learn from all this? According to Charles F. Sabel, today's organizational revolution seems to tie organizational success to the very ability to challenge habit and routines (Sabel 2005). In this light, ongoing processes of casting doubt on ones current routines and work habits combined with a continuous search for innovative change is important for organizational competitiveness.

By exploring the constructive links between cooperation, rivalry and learning within the structure of team communities, I have observed that rivalry and co-operation constitute two important learning processes; that in a supplementary way tend to facilitate the production of new ideas, the aspiration to find smarter ways to work, and establish a work environment where doubt and curiosity towards the existing work practice create the basis for innovative changes and continuous improvements. Such dynamics, however, seem to presuppose a sensed "we" both within the teams, as well as towards the wider community of teams. Constructive relations of rivalry as a vital source for mobilizing learning processes may, in other words, not flourish alone. Therefore, the team community must continuously balance rivalry and relations of cooperation in order to mobilize dynamic learning-processes. The question is how such a balance can be developed and supported? The answer is tricky and multi-faceted. But I believe, that an awareness of the well known saying: you can not design learning but you can design for learning, is important to bear in mind. In this respect I have hopefully, demonstrated that monitoring these micro-collective dynamics of learning calls for managerial action and organizing principles, which acknowledge that not only harmonious co-operation but also rivalry is closely related to the learning capabilities within team-based organizational life. 


\section{References}

Agyris, C \& D. A. Schön 1996: "What is An Organization That It May learn?", i Organizational Learning II - Theory, Method, and Practice. Addison- Wesley publishing Company.

Arnal, Elena, Wooseok OK and Raymond Torres (2001). "Knowledge, Work, Organization and Economic Growth", OECD Labour Market and Social Policy Occasinal Papers, No. 50; OECD Publishing.

Asplund, Johan (1972). Om undren overfor samfundet. Hans Reitzels forlag. København.

Asplund, Johan (1989). Rivaler och syndabuckar. Bokförlaget Korpen. Göteborg.

Bacharach, Michael (2005). "Foreword: Teamwork". In Natalie Gold eds. Teamwork - MultiDisciplinary Perspectives. Palgrave Macmillan.

Bacon, Nicolas and Blyton, Paul (2000). "High road and low road teamworking: Perceptions of management rationales and organizational and human resource outcomes". Human Relations, 53(11): 1425-1458.

Benders, Jos (2006). “Team Working: A Tale of Partial Participation”. In Harley, Hyman and Thompson eds. Participation and Democracy at Work. Palgrave Macmillan, London/Basingstoke.

Benders, Jos and Hootegem, Geert Van (1999). "Team and their Context: Moving the Team Discussion beyond Existing Dichotomies”. Journal of Management Studies, 36:5: 609-628.

Benders, Jos, Huijgen, Fred and Pekruhl, Ulrich (2002). "What do we know about the incidence of group work (if anything)?”. Personnel Review, Vol. 31 No. 3: 371-385.

Bottrup, Pernille (2002). "At skabe rum for læring i arbejdslivet”, i Illeris (red.) Udspil om laring $i$ arbejdslivet. Learning Lab Denmark. Roskilde Universitetsforlag

Bramming, Pia (2006). Competence-in-practice: The Contribution of Social Learning Theory to a Social Conceptualization of Competence. Working paper, CBS.

Brown, J. S. \& P. Duguid (1991): “Organizational learning and Communities-of-Pratice: Toward a unified view of working, learning and innovation ", in Organization Science. Vol. 2, No.1.

Casey, Catherine (1995). Work, Self and Society -after Industrialism. Routledge, London.

Dewey, J (1916) Democracy and Education: An introduction to the philosophy of Educations, New York: The Free Press, 1966

Elias, Norbert (1978). What is Sociology? Hutchinson \& Co (Publishers) Ltd 1978. 
Elkjær, B. (2000) "Learning and getting to know: the case of knowledge workers" in Human resource Development International. 3:3, 343- 359.

Elkjær, B. (1998) "The Continuity of Action and Thinking in Learning - Re-visiting John Dewey" Outlines 2000 - tjek !

Emirbayer, Mustafa (1997), "Manifesto for a relational Sociology". The American Journal of Sociology, Volume 103, No. 2., pp. 281-317.

Emirbayer, Mustafa and Ann Misch (1998), "What is Agency". The American Journal of Sociology, Volume 103, No. 4., pp. 962-1023.

Gheradi S. 2000. Practice-based Theorizing on Learning and Knowing in Organizations. Organization 7: 211-223

Gheradi S. 2001. From Organizational Learning to Practice-Based Knowing. Human relations 54: 131-139.

Gheradrdi, S., Nicolin, D., \& Odella, F. (1998). Towards a social understanding of how people learn in organizations. Management Learning, 29(3): 273-297.

Gold, Natalie (2005). Teamwork: Multi-diciplinary Perspectives. Palgrave Macmillan

Henriksson, Kristina (2000). When Communities of Practice Came to Town - On culture and Contradiction in Emerging Theories of Organizational Learning. Institute of Economic Research. Working Paper Series. Department of Business Administration. School of Economics and Management, Lund University, Sweden.

Hills, Howard (2001). Team-based Learning. Aldershot: Gower Publishing Limited

Hochschild, Arlie Russell (1997). The time bind -when work becomes home and home becomes work. 1st American ed Metropolitan Books, New York.

Hvenegaard, Hans; Helge Jessen \& Peter Hasle (2003). Gruppeorganiseret arbejde - På vej mod bedre arbejdsmiljo og konkurrenceevne? Frydendal, København.

Kolb D. A. 1984. Experimental Learning. Experience as the source of Learning and Development. Englewood Cliffs: Prentince Hall.

Kristensen, Peer Hull \& Maja Lotz (2005). Taking Teams Seriously as Economic Actors: Towards a Sociology of Team Behavior. Working Paper. Paper prepared for the 9th International Workshop on Teamworking (IWOT 9). Monte de Carparica (Lisbon).September 8-9, 2005

Lind, Mads (2000). Relations former i professional fodbold. Sociologisk Institut, Københavns Universitet. 
Procter, Stephen and Currie, Graeme (2004). "Target-based teamworking: Groups, work and interdependence in UK civil service”. Human relations, 57(12): 1547-1572.

Pruijt, Hans (2002). "Neo-Tayloristic and anti-Tayloristic Models of Team-working”. Paper presented at the IAS World Congress og Sociology, Researc Committee 26, July 7-12 2002.

Sabel, Charles F. (2005). "A Real-Time Revolution in Routines”, in Heckscher \& Adler eds. The Cooperation as a Collaborative Community.

Senge, Peter (1990). The Fifth Discipline: The Art and Practice of the Learning.

Sennett, Richard (1998). The Corrosion of Character

-the personal consequences of work in the new capitalism. Norton, New York.

Shusterman, Richard (1999). "Dewey on Experience: Foundation or reconstruction?" In Casey Haskins and David L. Seiple eds. Dewey Reconfigured - Essays on Deweyan Pragmatism. State University of New York Press, Albany.

Simmel, Georg (1971). On Individuality and Social Forms - Selected Writings. (Ed.) Donald N. Levine. The University of Chicago Press. Chicago and London.

Sinclair, Amanda (1992). “The Tyranny of Team Ideology”. Organization Studies, 13: 611-626.

Wenger, Etienne (1997). Communities of Practice Learning, Meaning, and Identity. Cambridge: Cambridge University Press.

Wouters, Cas (1998). "How Strange to Ourselves are our Feelings of Superiority and Inferiority”. Theory, Culture \& Society. Volume 15, 131-150. 